\title{
Existe relação entre estresse oxidativo induzido por cisplatina e a presença de polimorfismos associados à detoxificação da cisplatina em pacientes com câncer de cabeça e pescoço?
}

Anna Paula L. Costa (IC), Eder P. de Carvalho (PG), Marília B. Visacri (PG), Bruna T. Tuan (PG), Guilherme A. da S. Nogueira (PG), Ericka F. D. Costa (PG), Leisa L. Aguiar (PG), Tathiane R. P. Lima (PG), Laís S. Amaral (IC), Daniele Baldini (IC), Priscila G. Mazzola (PQ), Carmen S. P. Lima (PQ), Patricia Moriel (PQ).

\section{Resumo}

Neste estudo pacientes com câncer de cabeça e pescoço que receberam tratamento antineoplásico com cisplatina e radioterapia foram analisados em relação aos marcadores de peroxidação lipídica, concentração de nitritos na urina e a presença de polimorfismos nos genes que codificam as enzimas glutationa-S-transferases (GSTM1, GSTT1 e GSTP1).

Palavras Chave: Estresse oxidativo, Polimorfismo, Glutationa-S-transferases.

\section{Introdução}

Os genes GSTP1, GSTM1 e GSTT1 codificam as glutationa-S-transferases P1 (GSTP1), M1 (GSTM1) e T1 (GSTT1), respectivamente. Tais enzimas são de extrema importância na detoxificação de fase II, envolvidas na conjugação de substratos tóxicos à célula, catalisando a conjugação da glutationa (GSH) a estes compostos $^{1}$, tornando-os mais hidrofílicos e mais facilmente excretados pela urina ${ }^{2,3}$. A GSH também é uma molécula antioxidante. Para que a cisplatina (CDDP) seja excretada, a formação de conjugados entre GSH e CDDP constitui um importante passo em sua inativação e eliminação das células. Ainda, sabe-se que a CDDP está relacionada com a geração de espécies reativas de oxigênio (EROs) e nitrogênio (ERNs), resultando em estresse oxidativo. Portanto, 0 objetivo deste estudo foi avaliar a relação entre 0 estresse oxidativo causado pela CDDP e sua relação com a presença de polimorfismos nos genes relacionados às glutationa S-transferases (GSTM1, GSTT1 e GSTP1).

\section{Resultados e Discussão}

Foram incluídos pacientes com câncer de cabeça e pescoço (CCP) que receberam tratamento antineoplásico com CDDP (70$100 \mathrm{mg} / \mathrm{m}^{2}$ ) e radioterapia. Neste estudo, as análises foram realizadas apenas após o $1^{\circ}$ ciclo de quimioterapia. Foram analisados marcadores de peroxidação lipídica (método de FOX-2 e TBARS) e concentração de nitritos (método de Griess) na urina de 48 horas após a primeira aplicação de quimioterapia com CDDP. Os genótipos dos polimorfismos GSTM1, GSTT1 e GSTP1 lle105Val foram analisados por meio da reação em cadeia da polimerase (PCR) multiplex e PCR seguida de digestão enzimática, respectivamente, em DNA de sangue periférico.

Avaliaram-se 21 pacientes, com idade média acima de 50 anos, maioria homens, brancos, com tumores de faringe, em estadio IV. Houve aumento do estresse oxidativo dentro das $48 \mathrm{~h}$ após tratamento com CDDP: 0,05 para $0,06 \mathrm{nmol}$ de TBARS/mg Creatinina; 3,46 para 5,93 $\mu \mathrm{mol}$ de peróxido/mg Creatinina; e 2,37 para 7,20 $\mu \mathrm{mol}$ de $\mathrm{NO}^{2-} / \mathrm{mg}$ Creatinina. Foi observada maior frequência para os genótipos GSTM1 deletado (61,9\%), GSTT1 presente (80,9\%) e GSTP1 heterozigoto variante lle/Val $(57,1 \%)$. Não houve correlação significativa entre os polimorfismos estudados e os biomarcadores de estresse oxidativo urinário (teste de Mann-Whitney, considerando $\mathrm{p}<0.05$ ).

\section{Conclusões}

Pacientes com CCP em tratamento com CDDP apresentaram um aumento na concentração de biomarcadores urinários de estresse oxidativo, entretanto, não houve relação entre a presença de polimorfismos associados aos genes de detoxificação de CDDP e estresse oxidativo.

\section{Agradecimentos}

Agradeço ao Apoio Financeiro do PIBIC/UNICAMP e da FAPESP.

${ }^{1}$ Oliveira AL et al. GSTT1, GSTM1, and GSTP1 polymorphisms and chemotherapy response in locally advanced breast câncer. Genet Mol Res. 2010;9(2):1045-53.

${ }^{2}$ Chen HH, Kuo MT. Role of glutathione in the regulation of Cisplatin resistance in cancer chemotherapy. Met Based Drugs. 2010:430939.

${ }^{3}$ Moyer AM et al. Glutathione pathway genetic polymorphisms and lung cancer survival after platinum-based chemotherapy. Cancer Epidemiol Biomarkers Prev. 2010;19(3):811-21. 